\title{
Eclesiología y sociedad en el siglo XIV. Análisis doctrinal en Marsilio de Padua*
}

\author{
Luis Rojas \\ UNIVERSIDAD DEL BÍO-BÍO (CHILE) \\ lrojas@ubiobio.cl
}

\begin{abstract}
Resumen: El artículo analiza la eclesiología de Marsilio de Padua. Se intenta demostrar, primero, que su propuesta eclesial se explica mejor por las circunstancias vividas por el autor que por su contexto histórico; y segundo, que su ideal de Iglesia no era realizable en su tiempo.
\end{abstract}

Palabras clave: Conciliarismo, eclesiología, potestad apostólica, soberanía.

Abstract: This paper analyzes Marsilio of Padua's ecclesiological thought. It tries to prove, first, that his proposal is better understood by considering the author's personal circumstances than by his historical context; and second, that his Church ideal was impossible to achieve during his time.

Keywords: Conciliarism, eclesiology, apostolic power, sovereignty

\section{INTRODUCCIÓN}

Una constante domina la historia de la Iglesia: la convivencia entre los papas y los concilios no ha sido siempre fácil ni fluida. A fines de la Edad Media, la tensión se extenderá por mucho tiempo, y tendrá su manifestación en los frecuentes roces que habrían de producirse entre la autoridad jurisdiccional que el Papa reivindicaba para sí desde Roma y la autoridad doctrinal que los concilios aseguraban tener. Con tamañas fuerzas poderosas en pugna, el riesgo de una desarticulación estaba siempre latente al interior de la Iglesia, de no haber prevalecido el carácter y la prudencia de parte de algunos pontífices, pero también de parte de los

Este artículo forma parte de una investigación mayor titulada "La idea de Iglesia en autores bajo-medievales (siglos XIV y XV)", financiada por FONDECYT ( $\left.\mathrm{N}^{\circ} 1130476,2013-2015\right)$. 
padres conciliares que intentaron, siempre que les fue posible, evitar los conflictos para superar las crisis ${ }^{1}$.

¿Por qué estudiar la eclesiología? Consideramos que en la condición intrínsecamente histórica de la Iglesia va impresa la historicidad de toda eclesiología, porque la historia de la Iglesia es, en verdad, el meollo central de la eclesiología. Como ninguna otra época de la Historia, los siglos XIV y XV nos parecen un período especialmente importante como aporte a la reflexión eclesiológica ${ }^{2}$. El principal objetivo que tuvo una literatura aparecida en esta época, fue limitar el control que el Papa tenía sobre toda la Iglesia, dándoles mayores atribuciones resolutivas al Concilio.

Este tema no ha dejado de estar presente en la historia posterior de la Iglesia $^{3}$. A fines del siglo XIX, la soberanía del Papado parecía inmutable, y la posibilidad de un nuevo concilio se consideraba fuera de lugar. $\mathrm{Si}$ en esas circunstancias solo algunos medievalistas se interesaban en la teoría conciliar del siglo XV, todo cambió cuando Juan XXIII hizo el llamado a un Concilio en 1959, poniendo en el tapete el problema acuciante del gobierno de la Iglesia y el rol del concilio en la vida eclesiástica. Entonces el libro de Brian Tierney sobre la teoría conciliar, escrito cuatro años antes para un público restringido de especialistas, durante el Concilio Vaticano I sirvió para demostrar que el tema por él estudiado tenía implicancias significativas para la moderna eclesiología ${ }^{4}$.

\section{LAS DOCTRINAS}

Para entender adecuadamente las doctrinas que surgieron debe ubicárselas en medio de la crisis. Solo así puede entenderse que se formu-

1 G. Alberigo, Chiesa conciliare. Identità e significato del conciliarismo (Brescia, 1981). E. F. JACOB, Essays in the Conciliar Epoch (Manchester, $\left.{ }^{3} 1963\right)$.

2 J. S. Madrigal Terrazas, La eclesiología de Juan de Ragusa O.P. (1390/95-1443) (Universidad Pontificia de Comillas, Madrid, 1995). D. Del Prete, "Dal Defensor Pacis al Defensor Minor: l'involuzione del pensiero religioso di Marsilio da Padova” in Itinerari di Ricerca Storica, Dipartimento di Studi Storici dal Medioevo all'Età Contemporanea, 19 (2005) 59-77. IDEM, "Il pensiero politico ed ecclesiologico di Marsilio da Padova", in Annali di Storia, dell'Università degli Studi di Lecce, 1 (1980) 17-124.

3 H. SCHNEIDER, Der Konziliarismus als Problem der neueren katholischen Theologie (Munich, 1976).

4 B. Tierney, Foundations of the Conciliar Theory: The contribution of the Medieval Canonist from Gratian to the Great Schism (Cambridge, 1955) 106. 
laran interrogantes como, ¿puede un Concilio ser convocado sin el consentimiento del Papa? ¿Tiene el Concilio autoridad sobre los pretendientes a la Santa Sede? Nada de esto era de fácil resolución, puesto que los argumentos tomados del derecho canónico, de la historia de la Iglesia y del Nuevo Testamento podían sostener las ideas en favor del Concilio como también favorecer la autoridad omnímoda del Pontífice.

De principio a fin, la principal cuestión fue justificar la intervención conciliar contra un Papa contumaz. Los conciliaristas invocaron el principio de "equidad" (epieikeia) para señalar que el derecho positivo puede ser completado por la justicia natural, que justifica a cualquier cuerpo o sociedad a recurrir a medios de urgencia cuando su unidad está amenazada ${ }^{5}$. Por lo tanto, en caso de urgencia, también lo puede hacer el cuerpo espiritual o místico de la Iglesia cristiana ${ }^{6}$.

Las doctrinas se elaboraron en medio de las circunstancias enfrentando la crisis. Por tal razón, pueden encontrarse aspectos en ellas que guardan relación con una reflexión profunda de la historia de la Iglesia, pero también se advierten argumentos puramente contingentes y actitudes de combate ${ }^{7}$. En primer lugar, respecto de los planteamientos de fondo, había que demostrar que no parece sensato creer que la Iglesia entera pueda resumirse en la figura del Papa, aunque la reforma impulsada por Gregorio VII en el siglo XI propugnara reedificar la Iglesia concibiendo al pontífice como la piedra angular ${ }^{8}$. Al contrario, ella está representada -y sostenida- por el Concilio General, es decir, por todos los representantes de todos los lugares de la cristiandad. De ello se deducía la siguiente afirmación de carácter radical: La Iglesia es superior al Papa.

5 F. OAKLEY, "Natural Law, the Corpus Mysticum and Consent in Conciliar Thought from John of Paris to Mathias Ugonis", Speculum 56 (1981) 789-810, esp. 797. B. Tierney, Religion, Law and the Growth of Constitutional Thought (1150-1650) (Cambridge University Press, 1982) 87.

6 Pierre D'Ailly, Propositiones utiles ad extinctionem praesentis schismatis per viam concilii generalis (1409), en Veterum Scriptorum Monumentorum Amplissima Collectio (edit. E. Martène y V. Durand, Paris 1733, vol. 7) col. 910. A. BLACK, "Popes and Councils", en The New Cambridge Medieval History (Cambridge University Press, 1988) vol. VII, 79-80. F. OAKLEY, Church History 29 (1960) 398-403.

7 J. Castello Dubra, "La eclesiología de Marsilio de Padua", en Bulletin du centre d'études médiévales d'Auxerre, Hors-série 7/ 2013 ("Les nouveaux horizons de l'ecclésiologie: du discours clerical à la science du social") 1-12.

8 S. Gouguenheim, La Réforme grégorienne. De la lutte pour le sacré à la secularisation du monde (Temps Présent, Paris, 2010). 
Si estas doctrinas podían implementarse solamente en caso de urgencia -puesto que habían sido pensadas en medio de la crisis-, o bien constituían principios permanentes, los canonistas no estaban todos de acuerdo. Algunos sostenían que el conjunto de obispos y cardenales constituidos en el Concilio, eran colectivamente superiores al Papa, aunque fraternalmente unidos, planteamiento doctrinal que podemos considerar de fondo. En otros términos, desde el punto de vista eclesiológico, este razonamiento nos viene a decir que la autoridad última en la Iglesia no está radicada en el Papa sino en el Concilio.

Este raciocinio puede explicarse tanto por razones circunstanciales como también de fondo: lo primero, que los obispos y los cardenales eran lentos en su actuación, poco atentos y ágiles ante la gravedad de crisis, y esta lentitud había sido, probablemente, una importante causa del desencadenamiento de las dificultades. Puede agregarse aquí que si un Papa se comportaba de modo escandaloso, como era la persistencia en la ruptura y con ello hacía peligrar la situación de la Iglesia, podía ser juzgado y depuesto por un Concilio, ya que este intervenía como su superior en virtud de la autoridad de toda la Iglesia, es decir, por razones de fondo9. Estos razonamientos se correspondían con las propias convicciones morales de los conciliaristas, doctrina que fue elaborada para responder al gran cisma.

Como se ve, los segundos fundamentos, es decir, las razones de fondo, referidos a los testimonios que las Sagradas Escrituras mostraban respecto de la autoridad superior que adoptaba la Iglesia entendida como comunidad, se fueron quedando a la zaga ante la gravedad de los tiempos. Ni qué decir tiene, ante la radicalidad de las actitudes, las respuestas también se hicieron radicales, porque la contumacia demostrada por los pretendientes al solio pontificio de persistir en la ruptura sin dar paso al consenso, convirtió a las consideraciones circunstanciales en planteamientos de fondo.

El fondo del asunto, pues, era la necesidad de formular la supremacía jurídica del Concilio. Pero dicha idea no podía presentarse sola, sin apoyo argumental y desprovista de un sistema coherente de ideas. Tal como la conocemos, los intelectuales que intervinieron la sostuvieron

9 B. Tierney, Origins of Papal Infallibility, 1150-1350: A study on the Concepts of Infallibility, Sovereignty and Tradition in the Middle Ages (éd. E. J. Brill, 1972) 31-44, especialmente 93 y ss. 
desde dos ámbitos teóricos: al interior de una teología filosófica, pero también, y muy especialmente, como teoría política. Frente al criticismo moderado del poder del Papa, a comienzos del siglo XIV aparecen doctrinas y concepciones que ponían en duda los fundamentos mismos de la eclesiología medieval, digamos un radicalismo contestatario. Dejando de lado esta vez la perspectiva evangélica de Guillermo de Ockham, puede distinguirse la mirada laicizante de Marsilio de Padua, de la cual nos hacemos cargo aquí.

\section{EL PENSAMIENTO DE MARSILIO}

Hijo de un notario de Padua, hizo estudios de derecho y medicina y fue rector de la Universidad de París (1312-3) ${ }^{10}$. Después de breves estadías en el Avignon pontificio y en Padua, regresa a París donde enseña lógica y metafísica de Aristóteles en la Facultad de Artes. Permanece en Alemania en la corte de Luis de Baviera, rival de Federico de Habsburgo, en conflicto con el papa Juan XXII. Este intelectual italiano se hallaba muy influido por el aristotelismo que campeaba por entonces en las universidades de Padua y París. En relación con la cuestión acerca de las relaciones entre el poder espiritual y el poder secular, reaccionó de manera extremista contra el mismo extremismo de la corriente hierocrática. En 1324 termina su Defensor pacis cuyos planteamientos fueron condenados por el papa Juan XXII en 1327, declarando hereje a Marsilio ${ }^{11}$.

El Defensor pacis es uno de los tratados más profundos y originales escritos a fines de la Edad Media acerca de las relaciones entre los poderes. Ciertamente, los vínculos de su pensamiento con las ideas políticas que vendrían después lo han adornado de modernidad. Pero la aprecia-

10 Marsilius von Padua, Defensor pacis (Herausgegeben von R. Scholz, Hanovre, 1932-3). Marsilio de Padua, El defensor de la paz (Estudio preliminar, traducción y notas e Luis Martínez Gómez, Tecnos, Madrid, 2009²). Marsile de Padoue, Le défenseur de la paix (traduction française, annotation et présentation par Jeannine Quillet, Vrin, Paris, 1968). Texto latino en edición bilingüe, Rizzoli, 2001 dirigida por Maria Teresa Fumagalli. Marsilio escribió otras obras: De translatione Imperio, el Defensor minor, el De jurisdictione imperatoris in causa matrimoniali.

11 Bula Licet iuxta doctrinam, 23 de octubre de 1327, en M.G.H., Const., VI, I, no 361, p. 265 ss. Caesaris Baroni, Annales ecclesiastici (Ludovicus Guerin, 1880, vol. 24) col. 323 a $27^{\text {b }}$. J. Miethke, De Potestate Papae. Die päpstliche Amtskompetenz im Widerstreit der Politischen Theorie von Thomas von Aquin bis Wilhem von Ockham (Mohr Siebeck, Tubinga, 2000) 232-5. 
ción de la historiografía ha sido controversial, puesto que a veces se ha percibido en la obra una complejidad y una sutileza más allá del propio Marsilio, y desde el punto de vista de la teoría de la ley, un perfecto positivista $^{12}$.

Gordon Leff ha señalado que suele presentarse a Marsilio de Padua como un espíritu irreligioso dispuesto a desestabilizar las bases del poder de la Iglesia con miras al triunfo del poder político, una suerte de precursor del moderno Estado laico ${ }^{13}$. No fue esa su actitud, porque no negó a la Iglesia sus atributos espirituales, sino que su preocupación se centró en pensar un funcionamiento armonioso de la sociedad, y la elaboración de una -digamos- "política cristiana"14, en la que el legislador humano establecería las leyes que convendrían a la naturaleza de las personas, y que estarían en armonía con la consecución de los fines del estado natural, es decir, la paz ${ }^{15}$. Con una mirada teológica identifica en el pecado y sus consecuencias el mal común de la humanidad, el que genera la discordia civil y aleja la anhelada paz.

Uno de los temas más recurrentes en el libro consiste en la denegación rotunda del poder coercitivo de la Iglesia, o poder temporal. En su opinión, era un error suponer que la Iglesia haya sido fundada para estar eximida de los impuestos ordinarios o tener tribunales propios, esto es, que pudiera tener alguna autoridad coercitiva independiente ${ }^{16}$.

Anticipándose a lo que planteará Wyclif después, Marsilio opone la Biblia a los decretos papales. Su especial postura metafísica parece expli-

12 B. Bayona Aznar, Bernardo, «El periplo de la teoría política de Marsilio de Padua por la historiografía moderna», en Revista de Estudios Políticos 137 (2007) 113-153. G. DE Lagarde, Georges de, La Naissance de l'esprit lä̈que au déclin du Moyen Âge, Louvain, 1956-73. II (1958) 204 ss. A. GewirTh, Marsilius of Padua. The defensor of Peace, Macmillan, 1951, vol. 1, 134-5. J. Quillet, La Philosophie politique de Marsile de Padoue (J. Vrin, Paris, 1970) 135 y 139. J. MÉnARD, "L'aventure historiographique du Défensor de la paix de Marsile de Padoue", en Science et Esprit, 41 (1989) 287-322.

13 G. LefF, Heresy in the later Middle Ages. Relation of heterodoxy to dissent c. 1250-c. 1450 (special edition for Sandpiper Books Ltd., 1999) 415.

14 C. Nederman, Community and consent. The Secular Political Theory of Marsiglio of Padua's "Defensor Pacis" (Rowman \& Littlefield, Lanham, 1995) 14 ss.

15 Marsilio de Padua, Defensor pacis, I, $14 \$ 4$ ss. B. Bayona, "La paz en la teoría política de Marsilio de Padua”, en Contrastes. Revista Internacional de Filosofía 11 (2006) 45-63.

16 Marsilio de Padua, Defensor pacis, I, $2 \$ 7 ;$ II, 4, 9; $5 \$ 3 ;$ II, $17 \$ 18$. 
car que haya asumido una suerte de fundamentalismo al declarar que la Sagrada Escritura es la base de toda verdad canónica. Por cierto, en ello nada nuevo decía, pues era en cierto sentido universalmente aceptado. En lo que se apartó fue al oponerse a que la infalibilidad de la Biblia estuviera al arbitrio de la incertidumbre de las tradiciones humanas, con lo cual el llamado Magisterio de la Iglesia, con todo lo que contiene, quedaba en parte en entredicho. En caso de duda, ninguna autoridad divina -incluidos papas, cardenales y obispos- ni humana tenía atribución para determinar lo que era artículo de fe, sino solamente la interpretación de un Concilio general, cuya garantía la daba la asistencia del Espíritu Santo ${ }^{17}$. Únicamente puede explicar este principio marsiliano su concepción de la Iglesia como "el conjunto de los fieles" (congregatio fidelium).

Sin embargo, aun con esta aparentemente rotunda afirmación, Marsilio no debería ser considerado un real conciliarista, pues no estaba especialmente preocupado por las vicisitudes del Concilio ${ }^{18}$ ni su visión radicalizada fue recogida por el conciliarismo del siglo $\mathrm{XV}^{19}$. En cambio, sí estaba convencido de que la convocatoria a dicha reunión correspondía al legislador humano, al conjunto de los fieles o a su parte más importante (valentior pars), y las decisiones de esta parte debían ser confirmadas por el "gobernante", es decir, la comunidad ${ }^{20}$. Su antipapalismo impacta en el corazón de la doctrina eclesiástica, ya que al negar el derecho que reclamaba el Papa a la supremacía del gobierno en la Iglesia, negó también la suprema jurisdicción sobre ella. Tanto el poder temporal de la Iglesia como también los cimientos de la autoridad papal, hasta entonces aceptados, quedaban en este texto cuestionados y rechazados con argumentos históricos.

Sigamos la argumentación del paduano. Si la autoridad del legislador humano fue sustraída de la Iglesia, no fue por razones puramente seculares. Al contrario, nacieron de la concepción que San Agustín tenía de un Dios omnipotente que participa en todos los actos humanos. Partiendo de esta noción agustiniana que definía a la Iglesia como la congregatio fidelium, Marsilio procuró disminuir la distinción entre la clerecía y el

Marsilio de Padua, Defensor pacis, II, $18 \$ 8$.

18 G. LefF, Heresy in the later Middle Ages..., p. 418.

19 F. OAkley, The Conciliarist Tradition. Constitutionalism in the Catholic Church. 1300-1870 (Oxford University Press, 2003) 102-5.

20 Marsilio de Padua, Defensor pacis, II, $21 \$ 3$. W. Ullmann, Medieval political thouhgt (Harmondsworth, 1975) 204-14. 
resto de la feligresía, señalando que Dios actúa sin previo ministerio del sacerdote sobre el fuero de la conciencia del pecador arrepentido, iluminándole la mente y purificándole la culpa. Operando antes de la confesión ante un sacerdote, estas acciones revelan para Marsilio que el perdón del pecado puede y llega sin la mediación de un cura ${ }^{21}$. No obstante, no debe dar pie a pensar que tuviera una concepción esencialmente anti-sacerdotal de la religión, ya que no pretende conmover las bases doctrinarias de la Iglesia. Después de todo, debe reconocerse que su reflexión transita dentro de los presupuestos básicos que caracterizan al pensamiento medieval anterior a la Reforma.

A esto ha de agregarse su pensamiento sobre el Estado como detentador del poder político y también responsable del bien común. Postulaba que el gobernante supremo, asumiendo una función vigilante y a la vez represora, debía controlar la vida religiosa y organizar el culto. Cautelando la verdad de la religión y del culto se podía satisfacer el bien supremo del hombre en este mundo, como asimismo el bien de la comunidad entera. Todo ello podía lograrse cuando a los ministros de la Iglesia se les haya privado de todo poder coactivo, los cuales solamente podrán predicar la palabra e impartir los sacramentos ${ }^{22}$.

No parece sensato reconocer en la persona de Marsilio un "precedente" de alguno de los aspectos del ideario de la filosofía política moderna, y Gordon Leff cree que no puede deducirse que la independencia del poder político, planteada como lo hace el paduano, implique que haya pensado la noción de separación entre la Iglesia y el Estado. Su aristotelismo le habría llevado a poner todo dentro de las competencias de la comunidad, que es justamente lo contrario de excluir a la Iglesia ${ }^{23}$. Estando inmerso en las categorías aristotélicas, Marsilio muestra un destello de agustinismo cuando afirma que si Adán no hubiese pecado, no habría sido necesaria la autoridad civil $^{24}$. En esa línea, si el pueblo es la primera causa eficiente de la ley por la cual el rey regula la sociedad, la

21 Marsilio de Padua, Defensor pacis, II, 6, $\$ 6$.

22 B. Bayona, El origen del Estado laico desde la Edad Media (Tecnos, Madrid, 2009) 246. C. H. Mcilwain, The Growth of Political Thought in the West (Macmillan, New York, 1932) 313.

23 G. Leff, Heresy in the later Middle Ages..., p. 414. G. Garnett, Marsilius of Padua and "The truth of History" (Oxford University Press, 2006) 118.

24 Marsilio de Padua, Defensor pacis, I, $6 ₫ 2$-3. 
voluntad de Dios es su formal y última causa ${ }^{25}$. Ciertamente, puesto que allí donde el Estado moderno goza de absoluta soberanía, el gobierno pensado por Marsilio está obligado y sometido a la ley divina. Incluso en el evento de que existiera un conflicto entre los preceptos divinos y los humanos, los primeros deben obedecerse, aunque no explicite de qué modo $^{26}$. Por tal razón, de acuerdo con los fines de la sociedad, afirma Marsilio, la Iglesia es necesaria.

Además, era de opinión que al inmiscuirse en los asuntos políticos, algunos papas, apoyados en la doctrina de la "plenitud del poder", habían perturbado el orden de la sociedad al querer someter a su autoridad al Emperador, fundados en la pretensión de disponer de la jurisdicción temporal ${ }^{27}$. La importancia de la paz como deseo político introdujo la forma del Imperio como solución aparente del problema de la discor$\mathrm{dia}^{28}$. Al poner su confianza en el Emperador como guía de la cristiandad, Marsilio se mostraba tan anacrónico como los hierocráticos, pues soñaba con un Imperio cuya misión temporal y a la vez espiritual, conduciría a la humanidad a la salvación.

Desde la época de Constantino, y por su causa, la Iglesia desvió su camino y ha fallado en su misión, precisamente cuando aceptó lo que no debía: el poder y la riqueza, que la involucró en el llamado agustinismo político. Gradual y secretamente, dice, el primado romano, fundado en un principio sobre los mártires Pedro y Pablo, se acentuó y transformó en tiranía y fuente de corrupción cuando fue oficializado por Constantino. La plenitudo potestatis que ostenta el Papa romano, es la causa que explica tanto la corrupción misma, como asimismo la miseria de Italia y el Imperio ${ }^{29}$.

Para devolver el estado de cosas a un "orden", arguye que es necesario restituir a la Iglesia los cimientos de su forma primitiva, estos son, la pobreza y la humildad, despojándola de sus bienes y de toda soberanía. Puede vislumbrarse que esta reforma pasa, en primer lugar, por poner en duda la autoridad pontifical que, a su juicio, no viene inmediatamente

\footnotetext{
Marsilio de Padua, Defensor pacis, I, 9, $\$ 2$.

Marsilio de Padua, Defensor pacis, II, 5, $\$ 4$.

Marsilio de Padua, Defensor pacis, II, 23-24.

28 A. Boureau, La réligion de l'État. La construction de la République étatique dans le discours théologique de l'Occident médiéval (1250-1350) (Belles Lettres, Paris, 2006) 128.

29 Marsilio de Padua, Defensor pacis, II, 26.
} 
de Dios, sino por la decisión y la voluntad de los hombres (origen puramente humano), exactamente como cualquiera otra función en la sociedad; y en segundo lugar, situar correctamente el rol eminente del soberano, el "defensor de la paz", en la reforma de la Iglesia y de la sociedad. Como buen aristotélico, tiene una visión organicista de la comunidad política, y afirma que el poder reside en la comunidad de los ciudadanos que lo delegan en los príncipes, quienes se encargan de elegir al Emperador, legislador supremo que solamente puede estar sometido a la ley divina ${ }^{30}$. Si el poder soberano pertenece a toda la sociedad cristiana, este debe ejercer todos los poderes de jurisdicción, comprendiendo en estos también el ámbito religioso, ya que le corresponde, por ejemplo, castigar a los herejes ${ }^{31}$.

Nos encontramos ante un imperialismo secular que se explica por su convicción de la radical indivisibilidad del poder y su origen único, inmediatamente humano, pero remotamente divino. Así como el gobierno ha de ser único, la sociedad, concebida como un cuerpo, no puede tener dos cabezas y dos organizaciones. Se aparta del dualismo político que concibe a la Iglesia (sacerdotium) y al Estado (imperium) como dos poderes diferentes instituidos por Dios, los cuales están obligados a distribuirse y disputarse los respectivos ámbitos de acción. Marsilio cree que el poder espiritual no debe tener ningún reconocimiento civil, porque lo que impide la paz es la existencia misma de dos poderes que rivalizan la dirección de la sociedad (societas fidelium). El problema central para él no es definir la naturaleza y los fines del poder, ni tampoco establecer la relación más adecuada que deban tener lo político y lo religioso, esto es, subordinación o coordinación, sino entender que el poder tiene un fundamento intrínsecamente racional.

Su propósito fue elaborar una definición de las normas humanas que, necesariamente, dejaría el establecimiento de la ley secular en las manos de los laicos. En efecto, en su razonamiento, primero, deja de lado la ley natural (que la considera como una suerte de ley positiva), segundo, sitúa los efectos de la ley divina en lo venidero y tercero, niega la validez de la jurisdicción eclesiástica. De este modo, tuvo la convicción de haber suprimido el basamento que permitía al clero reivindicar su derecho a

30 Marsilio de Padua, Defensor pacis, XII, 9.

31 Marsilio de Padua, Defensor pacis II, 8, 9; III, 2, 15. G. LefF, Heresy in the Middle Ages..., 412 ss. 
intervenir en la ley secular y en el gobierno ${ }^{32}$. Situándonos siempre en la Edad Media, es difícil pensar en qué situación había de quedar la Iglesia en este razonamiento, acaso como una supra-organización socialmente semi-etérea guiando espiritualmente a la feligresía. Su carencia de poder coactivo político y social, reservado al monarca, convertía a este en un cuasi-Papa, contemporizador no solo en asuntos políticos, sino también religiosos. Nos parece un proyecto históricamente inviable, dado que el cristianismo no era entonces una mera religión, como la Ilustración nos ha enseñado a entender, sino un modo de vida, una civilización.

Muy significativa en su pensamiento es la idea de "la parte más importante" o "mejor parte" (valentior pars), donde se encuentra la idea que los cientistas políticos llaman representación por delegación. Al preferir la monarquía electiva, a la que consagra varias páginas en su Defensor pacis, Marsilio no considera incompatible el concepto de soberanía popular con la unidad. Al aplicar estos principios a la Iglesia, aparece su visión del Concilio general, opuesto al poder total del Papa, elaborado sobre la base del consentimiento y la representación. La Iglesia es el conjunto de fieles y el Concilio está constituido por los miembros que la representan. La representación del conjunto de ciudadanos por la "parte más importante", cualquiera sea la forma del poder, se corresponde con la representación del conjunto de fieles por esa "parte más importante"33. La Iglesia la forma la "reunión de los fieles" (congregatio fidelium) y ella está representada por el Concilio general. Se trata de una representación por delegación, porque el Concilio está integrado por clérigos y laicos elegidos, que son mandatados por los miembros de la Iglesia universal para normar las cuestiones concernientes a la fe. Los derechos de los fieles son confiados a la parte más importante del concilio ${ }^{34}$.

Siguiendo esta línea, Marsilio no establece una diferencia teórica entre comunidad política y comunidad religiosa, con lo cual los conceptos de Iglesia y de comunidad se confunden. No es fácil entender cómo la "comunidad de fieles" puede ser fundada según la naturaleza, si no se recurre al argumento metafórico y analógico: la Iglesia es "la universalidad de los fieles que creen e invocan el nombre Cristo, y de todas las partes

32 Marsilio de Padua, Defensor pacis, I, $10 \$ 3$.

33 Marsilio de Padua, Defensor pacis II, 20, 2.

34 Marsilio de Padua, Defensor pacis II, 6, 12-3; II, 17, 5-6. 
de esta universalidad en cualquiera comunidad suya aun la doméstica"35. Ciertamente, no entiende la Iglesia como una comunidad en su sentido estricto, sino que la concibe según la célebre metáfora canónica del corpus mysticum, cuya acepción depende del contexto en que se la piense. Sin embargo, él prefiere utilizar la palabra "perfecta" para calificar una comunidad de fieles en la que el príncipe es también un fiel ${ }^{36}$. En otros términos, lo que hace que una comunidad política sea una comunidad perfecta, es el hecho de ser una comunidad de ciudadanos creyentes. La Iglesia es, pues, la comunidad perfecta.

Sobre este basamento puede aplicarse el procedimiento de la delegación a ambas realidades - política y religiosa- sin distinguir diferencias. De esta manera, el legislador llega a ser el "creyente legislador humano", y las mismas estructuras políticas hacen de la "mejor parte" (pars valentior) capaz de representar al conjunto de ciudadanos creyentes. Abstractamente entendida como una persona ficta, digamos como populus, la sociedad política puede establecer un conjunto de normas que pueden aplicarse a la Iglesia, de manera tal que el principio representativo, al mismo tiempo que el consentimiento y la elección, pueden aplicarse plenamente a la composición del Concilio. Si el "conjunto de ciudadanos" (universitas civium) delega su autoridad en la "mejor parte" (pars valentior), la universalidad de los creyentes (universitas fidelium) confía sus derechos a la pars valentior de los creyentes.

Considerables son las consecuencias que en el plano eclesiológico tiene la doctrina política de Marsilio. Con tono rotundo, afirma que en la Cristiandad de su tiempo el Papa representa el principal enemigo de la paz, y por ello la reforma de la Iglesia debe considerar prioritariamente una nueva concepción del poder. Se trata de entender que el poder no reside en la jerarquía sino en la comunidad de los fieles que son, al mismo tiempo, y ante todo, ciudadanos del reino ${ }^{37}$. Usando una nomenclatura extemporánea, podemos interpretarle señalando que la Iglesia sería "democrática" en sus fundamentos, pero "representativa" en su funcionamiento, razón por la cual debería "democratizar" sus estructuras haciéndose "representativa": desde un punto de vista eclesiológico, solamente un concilio general puede atribuirse la inspiración del Espí-

\footnotetext{
35 Marsilio de Padua, Defensor pacis II, 2, 3.

36 Marsilio de Padua, Defensor pacis II, 17, 15. II, 25, 3.

37 Marsilio de Padua, Defensor pacis I, 19, 6.
} 
ritu Santo para interpretar la Escritura, que es la norma de referencia y de conducta de la Iglesia. Como puede apreciarse, su concepción de la Iglesia va más allá de lo históricamente posible.

Algunos intelectuales como Tomás de Aquino y Juan de Paris, siguiendo una posición dualista, habían entendido la naturaleza espiritual de la Iglesia y la naturaleza política del Estado, coexistiendo ambos en el mundo. Habida cuenta de que concebían a la Iglesia como una institución gubernamental, ellos reconocían la validez de la jurisdicción eclesiástica. Desde luego, con esta tesis se podía argumentar lo contrario, es decir, que si la Iglesia se concibe como un cuerpo místico de creyentes unidos por una comunión espiritual, puede recusarse la necesidad de un gobierno y, por lo mismo, de una jurisdicción. Por este sendero transitó Marsilio, aseverando que la Iglesia, y sobre todo la Iglesia romana, no debería gozar de ninguna autoridad en el mundo. La única jurisdicción aceptable debía recaer sobre las autoridades del Estado, puesto que la dimensión pública de la religión, necesariamente, concernía al Estado, y los clérigos, siendo ciudadanos, evidentemente, estaban bajo el control del Estado. Sin embargo, debe tenerse cautela si creemos ver en Marsilio de Padua una concepción moderna del Estado, esto es, su particular esencia secular. No es posible todavía el surgimiento de una visión enteramente secular de la vida humana en sociedad, razón por la cual Marsilio sigue siendo un intelectual medieval, ya que el conjunto de ciudadanos (universitas civium) era por él concebido como un conjunto de creyentes (universitas fidelium). Y todavía más, al considerar que la esencia de la ley humana tiene un carácter positivista -luego coercitiva-, no obstante con frecuencia, afirmaba, posee un contenido moral.

Igual situación podríamos presentar respecto de Dante Alighieri, que algunos años antes todavía conservaba su fe en el origen divino de la función de la cabeza de la Iglesia, distinguiendo entre la función del Papado como vicariato de Cristo y las personas que ocupando la silla de Pedro abusaban con un gobierno corrupto. Dante era, sin duda, partidario de una dualidad de dos poderes autónomos existiendo de manera coordinada al interior de la sociedad humana, pero su esperanza estaba en el Imperio ${ }^{38}$. En cambio, Marsilio fue original y violento. Anticipando la experiencia dramática de Lutero, Marsilio visitó la corte papal y

38 Dante Alighieri, Monarchia (ed. P. G. Ricci, Mondadori, 1965) lib. III. 
relató con repugnancia la corrupción del clero. Al abandonar la tesis dualista, atacó el corazón de la función vicarial.

Aun cuando se le ha considerado un conciliarista, creemos que, estrictísimamente, no lo es. A su juicio la reforma de la Iglesia no podría llegar a ser una realidad sin la participación directa del monarca, ya que, después de haber consultado al concilio (concebido aquí como una reunión de expertos), el soberano había de tomar todas las medidas necesarias para que triunfase el Evangelio, a saber, instituir a los clérigos, determinar su número, conceder el mínimo de recursos compatible con la necesaria pobreza. Así, retomando el camino de la perfección de sus orígenes, la Iglesia llegaría a ser en adelante una realidad puramente espiritual. Es curioso que una Iglesia así descrita, en parte se corresponda a la que existió durante el gobierno de Constantino, protegida y en parte dirigida por el poder político, y a la que Marsilio, no obstante, rechaza.

Se ve aquí que la Iglesia es a la vez espiritual y también temporal. La concepción espiritual de la Iglesia surge cuando al preguntarse por el rol de ella, señala que Cristo se excluyó él mismo y excluyó también a todos sus discípulos y sus sucesores de toda autoridad coercitiva o regla mundana ${ }^{39}$. Por cierto, al desconocer el origen divino de la función pontifical, no abordaba un tema nuevo, puesto que ya se había presentado dicha crítica. Sin embargo, la novedad estaba en que no provenía de posiciones heréticas, sino de un hombre perteneciente a las estructuras de la Iglesia. En un examen de carácter escriturístico y también histórico, niega la posición preeminente de Pedro y con ella, la primacía del obispo de Roma sobre toda la Iglesia. Desconoce la interpretación agustiniana del locus classicus del evangelio de Mateo donde se presenta la llamada "comisión petrina" (Mat. 16,18). Según esta visión, Pedro es identificado con la piedra sobre la que Cristo habría de construir su Iglesia. Marsilio objeta esta interpretación, ya que la piedra no puede ser Pedro sino Cristo, la única cabeza de la Iglesia. Y todavía más, afirma que lejos de haber pruebas de que Pedro haya sido obispo de Roma, es Pablo el que debería ser considerado el primer obispo romano ${ }^{40}$. Pero como no hay más cabeza en la Iglesia que Cristo, y este no fue obispo de Roma, los

39 Marsilio de Padua, Defensor pacis II, 4, 13. B. Bayona, Religión y Poder. Marsilio de Padua: ¿La primera teoría laica del Estado? (Biblioteca Nueva-Prensas universitarias, Madrid, 2007) 220-31.

40 Marsilio de Padua, Defensor pacis, II, 15-16. 
papas no pueden arrogarse la condición de sucesores. Así, la autoridad papal, sin un sustento divino, quedaba convertida en una institución puramente humana ${ }^{41}$. Estas ideas habrían de influir decisivamente en John Wyclif y en Jan Hus ${ }^{42}$.

Por lo tanto, la Iglesia fundada por Jesús no es en ningún sentido un cuerpo jurisdiccional, sino una congregación de fieles (congregatio fidelium), en cuyo seno los curas deben enseñar y exhortar al pueblo en su vida cotidiana a vivir cristianamente, corrigiendo y reprendiendo al pecador, pero en modo alguno obligando ${ }^{43}$. El rol crítico del poder espiritual estaba aquí negado.

Puede verse que el sistema elaborado por Marsilio de Padua constituía la antítesis completa de las concepciones hierocráticas. A una Iglesia deseosa de absorber al Estado, o al menos de controlarlo, él oponía un Estado que dominaba a la Iglesia, al tiempo que asignaba a la sociedad objetivos religiosos y morales elevados. Careciendo aquella de poder coercitivo, era preciso que se sometiera cada vez que la vida cristiana exigiera medidas de autoridad al "legislador humano creyente", el cual dispondría de los cargos eclesiásticos, convocaría los concilios, etc. La autoridad secular debía estar, definitivamente, libre de la tutela clerical. Como es posible advertir, su concepción de la sociedad era esencialmente cristocéntrica, no obstante procurara asimismo una suerte de desclericalización de la misma, visión en la que es preciso reconocer ciertos rasgos de modernidad, puesto que tuvo una actitud anti-sacerdotal, pero no anti-eclesiástica.

A diferencia de Guillermo de Ockham que se apoyó en la canonística, Marsilio de Padua lo hizo en la filosofía aristotélica y en su propia y particular interpretación de las Escrituras y de la Patrística. Como hemos visto, el grueso del argumento del Defensor Pacis está basado en una concepción esencialmente jurídica de la Iglesia y del Estado, como entidades corporativas, las cuales funcionan de acuerdo a las leyes normales de un cuerpo corporativo, fundado en el consentimiento de toda

\footnotetext{
41 Marsilio de Padua, Defensor pacis, II, cap. 28.

42 B. Bayona, El origen del Estado laico..., 253. G. Leff, Heresy in the later Middle Ages..., 416.

43 Marsilio de Padua, Defensor pacis, II, 10, 2.
} 
la comunidad, la cual se expresa a través de su "mejor parte", tomando en cuenta "la cantidad y calidad de las personas" ${ }^{4}$.

Las doctrinas de Marsilio fueron usadas por escritores tardíos, como lo estudia Paul Sigmund cuando establece su directa influencia en Dietrich de Niem y en Nicolás de Cusa citando pasajes de las obras de estos donde hay estrecha dependencia con similares pasajes del Defensor Pacis $^{45}$. En efecto, Nicolás de Cusa lo usó para probar que el gobierno legítimo debía fundarse en el consentimiento, y este debería ser la expresión de la parte más importante de la comunidad. Y Dietrich de Niem cita a Marsilio para probar que un Papa criminal o un Papa hereje debían ser depuestos, y que el Papa no posee el poder total de las dos espadas. Parece probable que, en efecto, hayan copiado los argumentos del paduano porque tuvieron a mano su obra, pero Brian Tierney cree que igualmente podrían haberlos tomado de las fuentes ortodoxas, esto es, de la canonística.

En ciertos aspectos, el irrealismo de sus puntos de vista no era menos que el de sus adversarios. Si Dante había recusado el hierocratismo en nombre de un dualismo, Marsilio discute el dualismo mismo y se opone a las posturas hierocráticas con un rotundo imperialismo. Con todo, quedarán un número de ideas que aflorarán después en diversos movimientos o corrientes reformadoras, como la naturaleza puramente espiritual de la Iglesia, el rechazo de toda jurisdicción eclesiástica autónoma, la superioridad de la Escritura con respecto a todas las decisiones pontificias y la desapropiación del clero en beneficio del poder civil.

Si nos situamos en una posición contextualista, esta obra respondería menos a la novedad de sus planteamientos que a las vicisitudes de una política local, de un destino humano particular, de la crisis imperial y de la presencia de franciscanos opuestos al Papa que daban un sello escolástico a su oposición. Incluso la carrera de Marsilio podría considerarse puramente local, apartándose de la posición güelfa que dominaba en su clase y llegando a ser gibelino como una manera de distinguirse. Ello seguirá siendo posible. Su formación universitaria también podría dar

44 B. Tienney, "A Conciliar Theory of the thirteenth-Century", en Catholic Historical Review 36 (1951) 415-40. W. Ullmann, Principles of government and politics in the Middle Ages (London, 1961) 283-6.

45 P. Sigmund, "The influence of Marsilius of Padua on XV ${ }^{\text {th }}$ - Century Conciliarism", en Journal of the History of Ideas 23 (1962) 392-402. 
luces, habiendo tenido dos estadías en París, en la segunda de la cuales llega a ser rector de la Universidad de París, cuyo ambiente era antipontifical ${ }^{46}$. También cabría preguntarse sobre la presunta modernidad de Marsilio en su planteamiento sobre la fuente del poder político, el origen de la sociedad, la naturaleza de la ley y otros asuntos. Igualmente, sería pertinente preguntarse si, dado que los temas tratados en su Defensor pacis son comunes a un ambiente más general y en contextos muy diferentes, fue realmente influyente en su momento. Las condenaciones a sus tesis se concentraron en su peculiar interpretación de la autoridad de Pedro, la distinción entre el sacerdote y el obispo, y en general la subordinación de la jerarquía eclesiástica al Emperador ${ }^{47}$.

\section{CONCLUSIÓN}

La primera etapa del conciliarismo ha sido nuestro interés en este artículo. La crisis vivida es la más profunda que haya tenido el Pontificado, puesto que la solución no estaba en manos de los pontífices en pugna, ni en los electores que disputaban las adhesiones. Al encontrar la solución en el Concilio se atentaba contra la tradición apostólica.

Los deseos de ver erigidas iglesias nacionales, e incluso estatales, eran aspiraciones que reflejaban bien el sentimiento religioso mayoritario de la población. Sin duda, los conciliaristas no eran cismáticos sino que creían no apartarse de la ortodoxia al afirmar que el Concilio era superior al Papa. Fue especialmente la historia de la Iglesia primitiva, como también la de los concilios ecuménicos, lo que iluminó la solución conciliar. Por ese camino desembocaron a posiciones radicales que incomodaron a una Iglesia monárquica, como asegurar que Pedro habría sido un primus inter pares y ello marcaba la posición de los pontífices sucesores; lo mismo acerca de las primeras controversias doctrinales, las cuales no las normaron los papas sino los concilios; con el fin de adaptarse a la época, algunos aspectos de la constitución de Iglesia podían ser modificados, puesto que eran producto de la experiencia histórica.

Entonces, frente a muchos errores cometidos por los papas, la garantía estaba radicada en el Concilio. Con argumentos tomados de la polí-

\footnotetext{
46 A. Boureau, La réligion de l'État..., 115-6.

47 G. Garnett, Marsilius of Padua..., 14-45.
} 
tica secular como también de la práctica de la Iglesia, se formularon propuestas como si fueran verdades generales aplicables a ambas realidades.

Las soluciones se apoyaron en razones circunstanciales como también de fondo: lo primero, el profundo desprestigio que afectaba al orden episcopal, causante en gran medida del estado de cosas. Las razones de fondo, esto es, la autoridad suprema que el Concilio había tenido desde los inicios del cristianismo, fueron perdiendo fuerza ante la gravísima situación. Las actitudes radicales generaron respuestas radicales, porque la contumacia de los pretendientes al solio pontificio de persistir en la ruptura sin dar paso al consenso, convirtió a las consideraciones circunstanciales en planteamientos de fondo.

Como se ve, el fondo del asunto era la necesidad de formular la supremacía jurídica del Concilio. Pero dicha idea no podía presentarse sola, sin apoyo argumental y desprovista de un sistema coherente de ideas. Tal como la conocemos, los intelectuales que intervinieron la sostuvieron desde dos ámbitos teóricos: al interior de una teología filosófica, pero también, y muy especialmente, como teoría política. Aquí se integran las ideas de Marsilio de Padua. 